\title{
The Cultivation Mode of the Computational Thinking for Economics and Management Professional
}

\author{
Ying Jia, Xiang Fang \\ Department of Computer Science, Shandong Institute of Business and Technology, Shandong \\ Province 264005, China \\ E-mail: jiaying0109@126.com
}

\begin{abstract}
Keywords: Computational Thinking; Economics and Management Majors; Fundamentals of Computers; Reform in education
\end{abstract}

\begin{abstract}
With the rapid development of the computer science and network technology, the capabilities of using computer for Economics and Management students in colleges are requested to be further improved and perfect. Now, however, the computer courses for the college Economics and Management professional exists the gap between the knowledge/skills instruction and demand for future computing capabilities, which causes a crisis in computer basic education. This paper proposes a way to deal with the crisis, which integrates the education of computational thinking with the Economics and Management professional. Based on this idea, the contents of the computer course are reconstructed to focus on the education of computing thinking, which will instruct a universal thinking for the computing disciplines. In addition, the thinking-type teaching methods of the college computer course are investigated.
\end{abstract}

\section{Introduction}

The objective of university education is to cultivate talent of comprehensive ability. University computer foundation, as an important part of university general education, which is accepted by students of non-computer majors as the first computer course, is very important . However, in many colleges and universities, the teaching focus on the use of certain office software, and students can only use software automatically and does not take the initiative to find new problems, and solve new problems, which will lead to students' difficulty in apply information technology effectively to their own work in order to solve practical problems. Therefore, in the face of society's growing demand for information ability, how to better improve the information literacy of college students is hot topics for education workers of college computer basic courses. In this paper, based on computational thinking, combined with many years of front-line teaching experience, author puts forward the positioning of this course, teaching content and teaching methods in computational thinking.

\section{Problems existing in computer basic education of administration for economic /management majors}

Most recently, with the depth of the popularity of computer and network, and computer application of the whole society improve, the process of information of all walks of life continue to accelerate. Theories of new information technology and application tools emerge in endlessly, such as online banking, e-commerce, the accounting computerization system, marketing system, the network financial information system, enterprise ERP system and so on, which puts forward new requirements to university computer foundation course that cannot just focus on the current popular software, and should be the relatively stable core content reflecting computer science idea and method, at the same time a more prominent way of thinking training. The computer courses for the college economics and management professional exist the gap between the knowledge/skills instruction and demand for future computing capabilities [1]. The main problems:

Instrumentalism is used as the basic starting point of computers fundamentals and the guiding 
ideology, there is undifferentiated universal education for various aspects of computer science, from computer architecture, operating systems, office automation to the multimedia technology, computer network, database and so on[2]. As knowledge involved is too comprehensive, and the function of each menu, rather than deep-seated thinking. Completion of this course and even learn the course well, students can only use compute more skilled, but comprehending for the computer is still very poor;

Lecture old result in student having no interest and enthusiasm in computer courses. In university of basic compute, knowledge or skills is taught, the way of thinking of computer science can be slowly enlightened out by the students instead being interpreted by teachers. And students think the course dispensable, whether learning good or not has nothing to subsequent courses, in addition boring content, most of students take assault to pass examinations;

The teaching model is old and lack of incentive mechanism. In current education pattern, we still continue the old teaching methods: in class, teachers teach; in a few laboratories, students operation. In highly informative recent, this single teaching methods becomes boring and tasteless, and caused many students more reluctant to undertake deep thinking. To a large extent, the teaching model greatly hinders the development of computational thinking, which is a common problem of Chinese computer basic teaching. For this reason, it is necessary to explore and try new teaching modes in order to mobilize students' potential, make students think, so that they have good practical skills, System of basic Knowledge and ability of computational thinking;

No research and practice combining the background of economics and management majors. The current courses practice of computer is mainly focused on common sense and general computer application ability, not combined with professional practical problems. No depth of understanding in their learning makes it impossible to develop the ability of students to solve practical problems in the industry.

\section{Computational thinking and teaching reform for computer basic in economics/management majors}

The phrase computational thinking was brought to the forefront of the computer science community as a result of an ACM Communications article on the subject by Jeannette M. Wing. The article suggested that thinking computationally was a fundamental skill for everyone in the world in the middle of the 21st century, not just computer scientists, and argued for the importance of integrating computational ideas into other disciplines. It should be with reading, writing and arithmetic (3R) as the essential qualities of the modern man[3].

As printing and publishing promoted the popularity of 3R, computing and computer contributed to the spread of computational thinking. We believe that the discourse of Jeannette M. Wing can be used as the ultimate goal of university computer foundation teaching. For economics and management majors, university computer foundation is one of the most important computer course, therefore, this courses should cultivate not only students' cognitive ability for computing environment, but also the ability for solving problem in the computing environment, which is an important foundation for students to apply computer technology to solve professional problems in the future. In addition, the computational thinking also provides a unique way of thinking, we should take into account the professional demand, change teaching content and teaching mode, and highlight the students' thinking ability, abandon the theory of "special tools", lay a solid foundation for he students' lifelong learning and good communication. How to integrate fundamentals of computer and professional knowledge to cultivate the students' thinking ability? We are doing a series of reforms:

A. Teaching objectives

In terms of the subject of university computer foundation, the author believe that the cultivation of the computational thinking can not only rely on a course, therefore, in this course we should not focus on the principle of computer and how it works, and should not teach the many popular application software and its application method, more should not teach how to program. After some of the most basic computer knowledge is taught, discuss about the core issues of the calculation. 
Specifically, students should meet the following requirements in this course:

Concepts about "calculation"; the reason of why the computer can be used to solve various problems. Understanding of the computer itself is no thinking ability, it's all work are a reflection of the human mind, its advantage is located in high-speed automatic.

Understand computer program is one of basic methods for men to solve practical problems, which is performed by command sequence. The whole and detail designed of the sequence is the embodiment of an art of the human mind.

The combination of computer and network far-reaching implicates of science and technology.

Students economics or management majors, can consciously try to thinking about how to use computer programs to solve in the face of practical problems, usually does not require them to design their program to solve the practical problems arising from the management. But the ability to quickly find and learn this program for the problem is necessary; Or, communicate to a computer programmer utility, design the program for solve the problem together.

\section{B. Course content}

Ministry of education of computer basic courses teaching steering committee put forward four basic ability training objectives for computer course in a non-computer major[4]. These four training objectives summarized as professional competence of computer science is the ability of the cognition and applications of the computer. These two capabilities is a perfect reflection of two core elements on the computational thinking: computing environments and problem solving. Therefore, $\mathrm{s}$ of computers should not only cultivate students awareness of the computing environment, but cultivate students to master the method for practical problem in a computing environment. Training skills of computational thinking is regarded as a central task of the fundamentals of computer, It has the following six units:

Calculation and calculation theory (calculation, calculated computational problem, Turing machine, von Neumann computer model, the new computer: quantum computing, molecular computing, optical computing, etc.) ;

Computer System Architecture (computer hardware, computer software systems);

Framework for problem-solving (description of the problem, model, calculation and verification);

Algorithms, data structures (algorithm definition, classification, representation; algorithm design, analysis, and commonly used algorithm);

The architecture of the computer network, local area network, Internet and application;

Social and information security.

C. Teaching process

Learning theory and instructional design principles proposed by Robert Mills Gagne, the famous American education psychologist, is the top achievement of the combination of scientific psychology and school education in the end of the 20th century. Its core idea is to design teaching for studying[5]. The nature of teaching is learning, teaching is to influence and promote the learners psychological acceptance by arranging appropriate external conditions. According my experience in teaching and the characteristics of the university computer basic course, combining with five process of Gagne theory, process of education is divided into: define goal/interest, review knowledge, imparting knowledge, provide study guides (answer questions, evaluate, and tutor extracurricular), feedback and enhance.

D. Teaching method

Regression style teaching: Computational thinking is highly abstract thinking, by which practical problems can be abstracted to the computer sign language. We must train students to understand the problem, analyze the problem and solve the problem in accordance with the problem-solving approach for computer. For freshman at this abstraction into ability is very lack, of some difficult to understand, boring, empty theory gradually lost interest in learning. It is very difficult for freshman students to understand the boring, empty theory and converse to abstract devise, and gradually lost interest in learning. In fact, a lot of theories originating in practice should return to themselves issues in the teaching process, and combined with the prototype of these theories to explain. which 
make originally obscure theory more specific and more close to real life. Regression and heuristic teaching method is a cycle from practice to theory, and then to practice again. with the continuous improvement of the understanding, the problem can be solved in a more abstract perspective.

guides style teaching: The guides style teaching that allow students to become the master of the class and the teacher to become learning guidance, focusing on method of learning, problem needed to be aware of, actively guide and change the thinking way of students, especially non-computer professional students in order to cultivate their reasoning skills, logical thinking ability, so as to possess basic ability of computational thinking. Sufficient time of training is needed for students to gain the ability of computational thinking. What to do the teacher needs to only is giving the topic, the relevant reference books, and the basic of thought for this problem, after class, students seek the way to solve the problem according to the materials, which improve constantly students' ability of computational thinking to understand abstraction, build the analysis modeling.

compromises professional knowledge across the barriers: Computer curriculum design combined with management knowledge is one of the effective ways to improve students' practical application ability, and students master the compute knowledge as the whole instead scattered learning through curriculum design, in which projects are completed independently as a team. Students who become active designers from passive receiver of information may select the topic that they are interested in, combined with professional knowledge; In addition, increasing co-operation in business professional and information engineering, contribute to break the boundaries of professional, training students to solve practical problems in small groups.

\section{Conclusion}

It is necessary and feasible to strengthen the cultivation of computational thinking in fundamentals of computers for students of economics and management professional. But because of the habit of thinking formed by the exam-oriented education for a long time, teaching reform about the integration of information education and financial professional will be a long-term process. More active exploration and practice of information literacy is not only the needs of the development of information economy, information society, but also needs of economics and management majors.

\section{References}

[1]D.J. Zhu, “Information Literacy Education and Professional Curriculum Integration”, Library Tribune 2012(5) , pp. 153-156.

[2]G.L. Chen,R.S.Dong, Computational Thinking and The college computer basic course, China University Teaching,2011(1),7-11

[3]J.M. Wing, "Computational Thinking," Communications of the ACM Viewpoint, Mar 2006, pp. 33-35.

[4]CFC, China Fundamental-computing Curricula 2009

[5]Robert Mills Gagne, "Principles of Instructional Design",Shanghai: East China Normail University Press. 